\title{
A FORMAÇÃO EM SERVIÇO DO GESTOR ESCOLAR COMO AÇÃO FORMATIVA INTENCIONAL E POLÍTICA
}

\author{
LA FORMACIÓN EN SERVICIO DEL GESTOR ESCOLAR COMO ACCIÓN \\ FORMATIVA INTENCIONAL Y POLÍTICA
}

\author{
THE TRAINING IN SERVICE OF THE SCHOOL MANAGER AS INTENTIONAL AND \\ POLITICAL FORMATIVE TRAINING ACTION
}

\author{
Marcelo do NASCIMENTO ${ }^{1}$ \\ Alessandro Luiz de OLIVEIRA ${ }^{2}$ \\ Rachel Duarte ABDALA ${ }^{3}$
}

RESUMO: Este artigo propõe a construção de um processo bibliográfico investigativo para elaboração de um processo sequencial de análises conceituais a partir de pesquisas, artigos científicos e livros temáticos, com o objetivo de demarcar um conceito específico de formação em serviço do gestor escolar. Em função da abundância de fontes sobre o tema, delimitamos os conceitos de formação continuada, educação (integral) continuada e formação em serviço, bem como as relações metodológicas entre prática e epistemologia nas formações continuadas. As análises culminaram no entendimento da gestão escolar como prática administrativa com características próprias, especialmente pelo aspecto político inerente à sua inscrição na dimensão educativa, característica que demanda igualmente uma formação em serviço com especificidades instrumentais e políticas.

PALAVRAS-CHAVE: Formação em serviço. Gestão escolar. Política.

RESUMEN: El presente artículo busca construir un proceso bibliográfico investigativo que procura elaborar un proceso secuencial de análisis conceptuales a partir de pesquisas, artículos científicos y libros temáticos, con el objetivo de delimitar un concepto específico de formación en servicio del gestor escolar. En función de las abundantes fuentes sobre formación continuada docente, delimitamos conceptos sobre formación continuada, educación (integral) continuada y formación en servicio, así como también las relaciones metodológicas entre práctica y epistemología en las formaciones continuadas. Como conclusión, se observó que la gestión escolar se entiende como práctica administrativa con características propias, especialmente por su aspecto político, inherente a su pertenencia a la dimensión educativa, demandando de igual forma una formación en servicio con especificidades instrumentales y políticas.

\footnotetext{
1 Universidade de Taubaté (UNITAU), Taubaté - SP - Brasil. Mestrando em educação. E-mail: marcelo.jirre@gmail.com

2 Universidade de Taubaté (UNITAU), Taubaté - SP - Brasil. Mestrando em educação. ORCID: <https://orcid.org/0000-0001-5473-2838>. E-mail: ale.luiz1@ gmail.com

${ }^{3}$ Universidade de Taubaté (UNITAU), Taubaté - SP - Brasil. Orientadora do programa de mestrado profissional em Educação. ORCID: <https://orcid.org/0000-0002-6936-5329>. E-mail: rachel.abdala@gmail.com
} 
PALABRAS CLAVE: Formación en servicio. Gestión escolar. Política.

ABSTRACT: This article aims to construct an investigative bibliographical process that seeks to elaborate a sequential process of conceptual analysis based on research, scientific articles and thematic books, with the purpose of demarcating a specific concept of in - service training of the school manager. Due to the abundance of sources on continuing teacher education, we use the concepts of continuing education, continuing education (in-service) and in-service training, as well as methodological relationships between practice and epistemology in continuing education. The analysis showed as result the understanding of school management as an administrative practice with its own characteristics, especially due to the political aspect inherent to its inclusion in the educational dimension, which requires in-service training with specific instrumental and political characteristics.

KEYWORDS: Training in service. School management. Politics.

\section{Introdução}

Objetivamos com o presente artigo estabelecer um percurso investigativo bibliográfico para demarcar um conceito sobre formação em serviço do gestor escolar.

Partimos de uma questão posta por Tardif e Raymond (2000), cuja provocação evoca uma dimensão ética quando problematiza a dissociabilidade entre o sujeito e o trabalho ao lembrar que as relações profissionais implicam sempre em um drama, o uso de si mesmo. Desse modo, se estabelece uma tensão em permanente campo de negociação entre os usos de si mesmo e o eventual uso de si pelos outros (TARDIF; RAYMOND, 2000).

Quando um professor leciona, não é a apenas a cessão de um serviço, como o desenhar de uma planta arquitetônica, mas sim um processo em que o próprio professor faz parte constitutiva da ação, como um integrante que opta por se entregar, misturar e modificar no processo. É uma discussão profunda porque questiona a opção de fazer algo de si mesmo em sua profissão e, simultaneamente, admitir, intencionalmente ou não, que alguma racionalidade, exterior a si, mas igualmente profissional, também dê sentido a sua identidade (TARDIF; RAYMOND, 2000).

Tem-se então um problema e uma pergunta que podem ou devem incidir igualmente, na mesma medida, sobre os processos formativos profissionais do gestor escolar. Independentemente da resposta que se possa dar, é preciso desvendá-la em função da intencionalidade que deve guiar escolhas formativas epistemológicas e metodológicas.

Nossa investigação conduziu a duas conclusões preliminares: a primeira, de que o tema “formação continuada" figura em volume muito superior à "formação em serviço" no campo 
de pesquisas e artigos acadêmicos, e livros. A segunda, de que a formação em serviço do gestor escolar figura de forma restrita em contraste com a formação em serviço docente.

Em função da abundância de fontes sobre o conceito de formação continuada docente, optamos por abordar referências cujas premissas metodológicas, seriam as mesmas daquelas destinadas ao gestor escolar.

Nesse aspecto, interessou-nos compreender e distinguir os conceitos de formação continuada e formação em serviço, de forma a referenciar nossa investigação a respeito da formação em serviço do gestor escolar e também compreender como se estabelecem as relações entre os campos epistemológico e prático. Com isso, propusemo-nos três frentes: a demarcação do conceito sobre formação em serviço; as relações entre epistemologia e prática no campo da formação em serviço; e, por fim, a demarcação de um conceito específico sobre formação em serviço do gestor escolar.

\section{Conceito de formação em serviço}

Formação continuada é um termo polissêmico. Está disseminado no mesmo campo de atuação de educação continuada e formação em serviço. Neste artigo, nosso objetivo é demarcar esse campo conceitual, basicamente apontando as diferenças entre formação continuada e formação em serviço.

Observamos em Chamon (2003) que historicamente, por volta dos anos 1950, o termo formação associa-se à noção de formação profissional e vincula-se com o universo educativo. A formação profissional tem inspiração em métodos americanos, em que figura o termo training, que se traduz como treinando ou treinamento. Formação profissional, em sua gênese, aproxima-se, nesse caso, de uma ideia de formação voltada ao aperfeiçoamento da prática técnico/profissional.

Quadro 1 - Referências a situações de formação continuadas contempladas na LBD 9394/96

\begin{tabular}{|l|c|c|}
\hline \multicolumn{2}{|c|}{ Campo 1: Todas as referências localizadas na LDB } & $\begin{array}{c}\text { Campo 2: Situações de } \\
\text { formação continuada }\end{array}$ \\
\hline Localização & Descrição dos trechos & $\begin{array}{c}\text { Relação com formação } \\
\text { situação de formação } \\
\text { continuada }\end{array}$ \\
\hline Artigo $40^{\circ}$ & $\begin{array}{l}\text { A educação profissional será desenvolvida em articulação com o } \\
\text { ensino regular ou por diferentes estratégias de educação continuada, } \\
\text { em instituições especializadas ou no ambiente de trabalho. }\end{array}$ & \begin{tabular}{c} 
Educação continuada \\
\hline
\end{tabular}
\end{tabular}




\begin{tabular}{|c|c|c|}
\hline $\begin{array}{l}\text { Artigo } 63^{\circ} \\
\text { Inciso III }\end{array}$ & $\begin{array}{l}\text { Programas de educação continuada para os profissionais de } \\
\text { educação dos diversos níveis. }\end{array}$ & Educação continuada \\
\hline Artigo $80^{\circ}$ & $\begin{array}{l}\text { O Poder Público incentivará o desenvolvimento e a veiculação de } \\
\text { programas de ensino a distância, em todos os níveis e modalidades } \\
\text { de ensino, e de educação continuada. }\end{array}$ & Educação continuada \\
\hline Artigo $2^{\circ}$ & $\begin{array}{l}\text { A educação profissional será desenvolvida em articulação com o } \\
\text { ensino regular ou em modalidades que contemplem estratégias de } \\
\text { educação continuada, podendo ser realizada em escolas do ensino } \\
\text { regular, em instituições especializadas ou nos ambientes de } \\
\text { trabalho. }\end{array}$ & Educação continuada \\
\hline $\begin{array}{l}\text { Artigo } 61^{\circ} \\
\text { Inciso I }\end{array}$ & $\begin{array}{l}\text { A associação entre teorias e práticas, inclusive mediante a } \\
\text { capacitação em serviço. }\end{array}$ & Capacitação em serviço \\
\hline $\begin{array}{l}\text { Artigo } 87^{\circ} \\
\S 3^{\circ} / \mathrm{III}\end{array}$ & $\begin{array}{l}\text { Realizar programas de capacitação para todos os professores em } \\
\text { exercício, utilizando também, para isto, os recursos da educação a } \\
\text { distância. }\end{array}$ & $\begin{array}{l}\text { Capacitação de } \\
\text { professores }\end{array}$ \\
\hline $\begin{array}{l}\text { Artigo } 87^{\circ} \\
\quad \S 4^{\circ}\end{array}$ & $\begin{array}{l}\text { Até o fim da Década da Educação somente serão admitidos } \\
\text { professores habilitados em nível superior ou formados por } \\
\text { treinamento em serviço. }\end{array}$ & Treinamento em serviço \\
\hline Artigo $9^{\circ}$ & $\begin{array}{l}\text { Art. 9o As disciplinas do currículo do ensino técnico serão } \\
\text { ministradas [...] professores, instrutores e monitores selecionados } \\
\text { [...], que deverão ser preparados para o magistério, previamente ou } \\
\text { em serviço, através de cursos regulares de licenciatura ou de } \\
\text { programas especiais de formação pedagógica. }\end{array}$ & Preparados em serviço \\
\hline $\begin{array}{c}\text { Artigo } \\
\S 1^{\circ}\end{array}$ & $\begin{array}{l}\text { Os novos planos de carreira e remuneração do magistério deverão } \\
\text { contemplar investimentos na capacitação dos professores leigos, os } \\
\text { quais passarão a integrar quadro em extinção, de duração de cinco } \\
\text { anos. }\end{array}$ & $\begin{array}{l}\text { Capacitação de } \\
\text { professores }\end{array}$ \\
\hline $\begin{array}{l}\text { Artigo } 13^{\circ} \\
\text { Inciso II }\end{array}$ & Capacitação permanente dos profissionais de educação; & Capacitação permanente \\
\hline
\end{tabular}

Fonte: produzido pelos autores com base na LDB 9394/96

Observa-se no quadro 1 que todas as referências a situações formativas abordadas na LDB apontam para a qualificação e aperfeiçoamento do professor para o exercício específico da sua função.

De acordo com Castro e Amorim (2015), antes da LDB, a formação continuada no Brasil assentava-se basicamente em duas linhas que seguiram paralelas a partir de 1970: a da reciclagem e a da capacitação. Enquanto a primeira atualizava, a segunda treinava o professor. Uma primeira análise do quadro demonstra que essas linhas ainda estão expressas na legislação.

A respeito da legislação sobre formação continuada, Estrela (2001) aponta como problema o fato de as leis serem balizadas por teorias acadêmicas sem a consideração da prática docente como fonte epistemológica.

Militão e Leite (2003), em estudo sobre a historicidade da formação continuada, aludem a quatro conceitos sobre formação continuada. 
Quadro 2 - Conceitos de formação continuada

\begin{tabular}{|c|}
\hline Autores e Definição \\
\hline Autor do cocneito: Cristiano Amaral Garboggini Di Giorgi \\
\hline $\begin{array}{l}\text { Processo constante do aprender a profissão de professor, não como mero resultado de uma aquisição } \\
\text { acumulativa de informação, mas como um trabalho de seleção, organização e interpretação da informação. }\end{array}$ \\
\hline Autores do conceito: Andréia N. Militão e Yoshie U. Ferrari Leite \\
\hline $\begin{array}{l}\text { Consistem geralmente em realização de oficinas, palestras, seminários e cursos de curta duração, } \\
\text { presenciais e a distância. }\end{array}$ \\
\hline Autor do cocneito: Bernadete A. Gatti \\
\hline $\begin{array}{l}\text { Encontra-se sob esta mesma denominação desde cursos realizados após a graduação até atividades } \\
\text { genéricas encaradas como possibilidade de contribuir para o desenvolvimento profissional como reuniões } \\
\text { pedagógicas, participação na gestão escolar, horas de trabalho coletivo na escola, congressos, seminários e } \\
\text { cursos de diferentes formatos }\end{array}$ \\
\hline Autor do cocneito: Vera M. Nigro Placco \\
\hline $\begin{array}{l}\text { Processo complexo que envolve a apropriação de conhecimentos e saberes sobre a docência, necessários } \\
\text { ao exercício profissional }\end{array}$ \\
\hline
\end{tabular}

Fonte: produzido pelos autores com base em Militão e Leite (2003)

A análise comparativa entre os quadros 1 e 2 indica a mesma incidência: situações formativas oferecidas em diferentes modalidades, mas com a mesma finalidade de propiciar conhecimento profissional para o professor em atividade docente.

Consonante à lógica dos conceitos do quadro n 2, Alarcão (1998) entende “[...]o processo de formação continuada como o processo dinâmico por meio do qual, ao longo do tempo, um profissional vai adequando sua formação às exigências de sua atividade profissional”. (ALARCÃO, 1998. p. 100). No mesmo sentido, Paula (2009) aponta que a formação continuada se caracteriza como propostas dirigidas a qualificação profissional, considerando seu aperfeiçoamento por meio de aquisição de conhecimentos. No que tange os métodos de sua área profissional, estes consistem em propostas voltadas para a qualificação do profissional, tendo em vista a possibilidade de melhoria de sua prática pelo domínio de conhecimentos e de métodos de seu campo de trabalho.

Salles (2015) basicamente identifica a formação continuada como uma segunda etapa da formação inicial. O autor usa o termo "formação continuada em serviço" para referenciar todas as ações formativas sistematicamente oferecidas pelos sistemas de ensino, ou aquelas produzidas na escola, no fazer docente, influenciado pelo contexto do trabalho.

\section{Formação continuada na perspectiva indenitária}

A formação continuada na perspectiva de situações formativas sistematizadas, partindo de uma intencionalidade. Salles (2015) aponta também para as situações assistemáticas, aquelas 
que ocorrem espontaneamente por conta das relações próprias do fazer pedagógico e no contexto da realidade.

Quadro 3 - Síntese conceitual sobre a formação a partir de identidade

\begin{tabular}{|l|l|}
\hline \multicolumn{1}{|c|}{$\begin{array}{c}\text { Autores do } \\
\text { conceito }\end{array}$} & \multicolumn{1}{c|}{ Definição } \\
\hline Antônio Nóvoa & $\begin{array}{l}\text { Professor como protagonista do conhecimento, produzindo sua efetiva formação nas } \\
\text { interações da profissão docente na escola. }\end{array}$ \\
\hline Donald Schön & $\begin{array}{l}\text { Intelectualidade atribuída à formação do professor: práxis de ação-reflexão-ação em } \\
\text { diferentes momentos do fazer pedagógico. }\end{array}$ \\
\hline Carlos Marcelo & Formação informal produzida nas rotinas das organizações. O contexto forma. \\
\hline Maurice Tardif & $\begin{array}{l}\text { Descreve quatro situações formativas, as vivências como aluno, a formação inicial, } \\
\text { o ingresso na profissão e as experiências ao longo da carreira. }\end{array}$ \\
\hline
\end{tabular}

Fonte: produzido pelos autores com base em Salles (2015)

A análise do quadro 3 torna visível as proposições de formação continuada que transigem entre si. Elas têm como elemento comum a centralidade no ambiente profissional e nas construções psicossociais, que se estabelecem para além de expectativas traduzidas em normatizações delimitadas pelos sistemas de ensino sobre como a prática do professor. Esta linha conceitual de formação continuada problematiza as relações de identidade do professor, neste campo, a identidade profissional docente seria um dinâmico e complexo equilíbrio em que a própria imagem do profissional tem que se harmonizar com uma variedade de papéis que os professores sentem que devem desempenhar. (MARCELO, 2009).

Com base na perspectiva de incompletude do conhecimento e da condição cognoscente humana de Freire (1997), a formação continuada estaria relacionada a todas as situações de aprendizagem que influenciam o desenvolvimento profissional e pessoal do professor com abrangência antes da formação inicial, fora do ambiente profissional e estendendo-se ao logo de todas as experiências de vida do professor. "Onde há vida, há inacabamento". (FREIRE, 1997, p. 55).

\section{Formação continuada integral}

Ao discutir a educação continuada, Moreto (2002) trata a formação continuada com maior abrangência. $\mathrm{O}$ “[...] uso do termo educação continuada tem a significação fundamental do conteúdo de que a educação consiste em auxiliar profissionais a participar ativamente do mundo que os cerca, incorporando tal vivência no conjunto dos saberes de sua profissão." (MORETO, 2002, p. 10). 
Para Castro e Amorim (2015), há uma oscilação flutuante de ordem conceitual sobre educação continuada. Os autores delimitam, porém, que a educação continuada não é uma concepção neutra de formação, mas identificada com os aspectos emancipatórios do professor, defendendo o engajamento do professor e dos sistemas.

A educação continuada contempla todas as oportunidades formativas que interfiram na formação profissional. Ou seja, aquelas que que precedem a profissão, como a vivência como aluno e a formação inicial (TARDIF, 2002), a formação continuada sistematizada e oferecida pelos sistemas educativos (ALARCÃO,1998), e a formação continuada produzida no contexto psicossocial da escola (NÓVOA, 2002). Educação continuada abrange também as interações com o universo cultural que o professor estabelece, relacionados ou não com sua profissão, mas que interferem na construção de sua identidade e que impactam direta ou indiretamente em sua prática.

Comparada com a formação continuada, a educação continuada traz uma dimensão mais abrangente, tratando da formação integral do professor não apenas como prática profissional, mas como prática social.

Quadro 4 - Síntese dos conceitos de formação continuada

\begin{tabular}{|c|c|c|}
\hline $\begin{array}{c}\text { Campo 1: } \\
\text { Instrumental/Normativa }\end{array}$ & 2: Pesquisa e reflexão & o 3: Pesquisa e reflexão \\
\hline $\begin{array}{l}\text { Formação que dá continuidade à } \\
\text { formação inicial. Oferecida em } \\
\text { diferentes modalidades pelos } \\
\text { sistemas educativos, com o } \\
\text { objetivo de capitar e aperfeiçoar a } \\
\text { prática específica do profissional. }\end{array}$ & $\begin{array}{l}\text { Formação a partir de aspectos } \\
\text { psicossociais. Constitui-se de } \\
\text { forma assistemática no contexto } \\
\text { da prática profissional, } \\
\text { influenciada pelo contexto. Não } \\
\text { tem um objetivo, tratando-se de } \\
\text { um fenômeno circunstancial da } \\
\text { prática. }\end{array}$ & $\begin{array}{l}\text { Formação integral. Abrange a } \\
\text { formação no sentido de } \\
\text { continuidade, também os aspectos } \\
\text { psicossociais da prática, e as } \\
\text { interações que se dão na inter- } \\
\text { relação do profissional com o } \\
\text { universo cultural, consideradas } \\
\text { formativas. }\end{array}$ \\
\hline
\end{tabular}

Fonte: produzido pelos autores com base nos dados bibliográficos

A análise do quadro 4 indica que as três variações sobre o conceito de formação continuada dividem-se em abrangência e modalidade. $O$ campo 1 revela uma formação continuada com bases legais e que se viabiliza por ações dos sistemas, redes e instituições de ensino em diferentes modalidades, como programas, reuniões de estudo, palestras, etc. A formação está direcionada ao profissional em razão de sua função e com o claro propósito de interferir em sua prática. Existe uma intencionalidade definida, seja para oferecer saber 
específico para habilitá-lo para a prática, ou para aperfeiçoar sua prática. Assim, apresenta teor normativo.

Os campos 2 e 3 procuram atender a proposição de Nóvoa (2002), na qual o cerne da formação não é entender como formar o professor, mas como ele se forma. Neste sentido, estas linhas conceituais, que variam basicamente em abrangência, irão problematizar a formação em si. O sentido é entender e valorizar os sabres docentes (TARDIF, 2002) com o propósito de alimentar e interferir em políticas públicas sobre valorização profissional, formação e formação continuada. $\mathrm{O}$ objetivo final é também interferir na prática, porém, com outra eficácia e com um viés social inerente ao papel do professor e da escola.

\section{Relações entre epistemologia e prática no campo da formação em serviço}

A partir da análise das linhas conceituais sobre formação continuada, e balizados pela abordagem de Alarcão (1988), delimitamos a formação em serviço todas as situações de aprendizagem oferecidas pelos sistemas, redes e instituições de ensino, para o profissional, em razão de sua prática específica, a análise deverá considerar os níveis de transigência com as outras lógicas de formação continuada.

Sobre formação continuada em serviço, Zeichner (2008) faz alusão a uma tensão fundamental chamada de dissociação entre formação acadêmica e formação prática ou entre racionalidade teórica e racionalidade prática. Uma relacionada a saberes acadêmicos e outra a saberes práticos.

Salles (2015), seguindo a mesma linha de Zeichner (2008), chama de racionalidade teórica (da teoria para prática) as formações representadas por teorias de reciclagem, capacitação e treinamento, cujas bases estão na noção externa e teórica de saberes que o professor deve saber para aperfeiçoar sua prática (quadro 1 e campo 1 do quadro 4). Por outro lado, Salles (2015) chama de racionalidade prática (da prática para a teoria), as concepções baseadas na formação a partir da perspectiva do sujeito. Ou seja, valorização da prática como ponto de análise para a formação (quadro 2 e campo 2 do quadro 4).

Marcelo (2009) discute e problematiza certa normatização da prática e da experiência. O autor chama de mito da prática a ideia de que a quantidade de experiências mantenha uma relação aritmética com a quantidade de formação e produção de conhecimento. Tudo dependeria da qualidade da experiência que se tenha. 
O professor não é um ser abstrato, não é uma ideia de professor. Ao contrário, é ser concreto, com identidade e eminentemente social (GATTI, 2003). Em grupo, ele partilha sua cultura, de onde emergem seus conhecimentos e suas atitudes frente as demandas da realidade escolar. "Daí decorre ser muito simplista a noção de que o aumento e a melhoria do rol de conhecimentos informativos, adquiridos individualmente, será suficiente para melhorar ou modificar conceitos e práticas ligados ao trabalho profissional de professores." (GATTI, 2003, p. 6)

Segundo Gatti (2003), programas formativos só mostram efetividade quando consideram as condições sociopsicológicas e culturais das pessoas, conseguindo, desse modo, criar mobilização de atitudes. "O que é preciso conseguir é uma integração na ambiência de vida e trabalho daqueles que participarão do processo formativo. (GATTI, 2003, p. 7)

Semelhantemente, Tardif (2002) aponta para uma formação que se pauta em um professor ideal, que nega a legitimidade dos saberes constituídos no ato de fazer e nas demandas práticas da escola, onde efetivamente são produzidos estes saberes. "Os pesquisadores mais se interessam pelo que professores deveriam ser, saber ou fazer, do que sobre o que são, sabem e sabem fazer." (TARDIF, 2002, p. 259).

Tradif (2002), estuda o que chama de epistemologia da prática profissional. Não se trata de um conceito, mas um tipo de vetor para orientar a pesquisa sobre o conjunto de saberes que o profissional mobiliza em seu local de trabalho para desempenhar todas suas tarefas. Conforme Tardif (2000), a docência não é um objeto a ser contemplado, mas uma atividade que, ao ser desenvolvida na prática, produz conhecimento e saberes próprios a epistemologia da prática. Portanto, não pode ser normativa.

De acordo com Nóvoa (2015), a formação docente privilegia a escola “[...] como o lugar da formação dos professores, como o espaço da análise partilhada das práticas, enquanto rotina sistemática de acompanhamento, de supervisão e de reflexão sobre o trabalho docente." (NÓVOA, 2015, p. 7). Sua proposição é que a produção de conhecimento individual dos professores seja transformada em conhecimento partilhado reelaborado e transformado em conhecimento coletivo.

Nóvoa (2015) aponta para um referencial de saberes docentes que abandona a saturação do termo competência e migra para o termo disposição. Este outro tem características menos rígidas, ou mais líquidas, e pretensão de um olhar dirigido a conexões entre as dimensões pessoais e profissionais na produção indenitária dos professores. 
[...] os professores não são apenas consumidores, mas também produtores de materiais de ensino; que os professores não são apenas executores, mas também criadores e inventores de instrumentos pedagógicos; que os professores não são apenas técnicos, mas são também profissionais críticos e reflexivos. (NÒVOA, 2002, p. 36).

Há a necessidade de se investigar aspectos constantes na identidade docente. Não se tratando da definição de competências, mas da busca em entender quem é este profissional, como se constitui e quais são os determinantes comuns de sua identidade que orientam suas escolhas (MARCELO, 2009).

Na perspectiva indenitária, procura-se estudar, compreender e espera-se determinada conduta profissional docente, “[...], mas não porque adotem características profissionais (conhecimentos e atitudes) prescritas. Os professores se diferenciam entre si em função da importância que dão a essas características, desenvolvendo sua própria resposta ao contexto. (MARCELO, 2009, p. 114)

Alarcão (1998) adjetiva como lugar comum a afirmativa de que a formação continuada deve centrar-se no professor, atribuindo ao docente o papel de sujeito e não objeto. Dessa forma, é tácita ao afirmar que qualquer formação que desconsidere a experiência e a realidade profissional, fatalmente estará desprovida de sentido para esse sujeito.

Como os demais autores, Estrela (2001) também vê a prática docente como cerne e alimento da formação. Para a autora, o docente é o sujeito de sua formação e ela também aponta as culturas organizacionais como determinantes do comportamento profissional. As culturas orientam as ações na medida em que orientam as escolhas. A forma com que se organizam os ambientes de trabalho, impactam na formação dos profissionais em três instâncias: instrumental, que se refere à escolha de técnicas; instância reguladora, que se refere às normatizações; e instância diretiva, que se refere à orientação dos valores e finalidades.

Para implantar mudanças em uma organização, há uma demanda de compreender que mudanças só são admitidas quando os sujeitos sentem que controlam o processo, sentindo-se partícipes e responsáveis pelo sucesso da proposta. Do contrário, deparam-se com uma negação interna, avessa às leis, normatizações e imposições, concorrendo para inviabilizar o sucesso de qualquer mudança (ESTRELA, 2001).

Este fator explicaria tanto os aspectos de ineficácia das formações, como as escolas não assumirem a autonomia que lhes outorga a legislação. "Para mudar é preciso querer ou sentir vontade de mudar ou, ao menos, é preciso que a mudança assuma um significado para aqueles a quem a mudança é imposta ou proposta.” (ESTRELA, 2001, p. 57). 
Vaillant e Marcelo (2012), quando tratam do tema da aprendizagem nas organizações, apontam que a problematização entre formação e ambiente de trabalho "[...] é um discurso assumido de forma generalizada no âmbito educativo [...] é um discurso assumido por pesquisadores, formadores, professores e inclusive pela administração educacional." (VAILLANT; MARCELO, 2012, p. 48).

As organizações - nesse aspecto enquadram-se as escolas - no modo que se organizam, definem uma cultura organizacional, um modo de fazer que é cultivado e perpetuado. Essa cultura provoca aprendizagens informais que são eficientes e que vão edificando o ambiente como lócus de formação.

Marcelo (2009), na perspectiva de Schön, explica três dimensões do conhecimento que se retroalimentam: a) conhecimento na prática: aquele produzido no ato do fazer. O momento das interações com a realidade dos professores que demandam posicionamentos e escolhas no ambiente escolar, enfrentamento de desafios e mobilização de saberes. Ponto inicial, pois está na prática; b) o conhecimento da prática: aquele que se alimenta da prática e reflete sobre ela. Tem a prática como seu objeto, portanto, é posterior a ela; c) conhecimento para prática: produto de análise e reflexão sobre a prática, formula teses e interfere, enquanto teoria, na prática, antecede a nova prática.

São dimensões distintas, mas interligadas, com mútua influência e papéis significativos. Os três conhecimentos têm um papel kantiano, conciliador no sentido de estabelecer uma relação dialética entre os três campos de saber.

Quadro 5 - Pontos convergentes na discussão entre teoria e prática

\begin{tabular}{|l|l|}
\hline \multicolumn{1}{|c|}{ Autores } & \multicolumn{1}{c|}{ Síntese das linhas conceituais } \\
\hline Antônio Nóvoa & $\begin{array}{l}\text { Professores não são apenas consumidores, mas também produtores de materiais de } \\
\text { ensino. }\end{array}$ \\
\hline Maria T. Estrela & Formação é indissociável do local de efetiva formação: a organizações de ensino. \\
\hline Maurice Tardif & Saberes docentes: importa conhecer e entende como os professores se formam. \\
\hline Isabel Alarcão & $\begin{array}{l}\text { Programas formativos dissociados dos saberes docentes não têm sentido para os } \\
\text { sujeitos. }\end{array}$ \\
\hline Bernadete Gatti & $\begin{array}{l}\text { Professores não são abstratos. Programas formativos devem considerar aspectos } \\
\text { psicossociais docentes. }\end{array}$ \\
\hline $\begin{array}{l}\text { Denise Vaillant e } \\
\text { Carlos Marcelo }\end{array}$ & $\begin{array}{l}\text { As organizações formam. A cultura do ambiente das organizações promove a } \\
\text { formação permanente e eficaz. }\end{array}$ \\
\hline Carlos Marcelo & $\begin{array}{l}\text { a) Legitimação dos campos de conhecimento: na prática, sobre a prática e para a } \\
\text { prática. b) Entendimento da identidade profissional como proposta de formação. }\end{array}$ \\
\hline
\end{tabular}

Fonte: produzido pelos autores com base na revisão de literatura 
Apesar do nível de aprofundamento nas linhas conceituais analisadas, a análise do quadro 5 indica que há um alto padrão de alinhamento entre as proposições sobre a relação entre teoria e prática na formação continuada.

O ponto de convergência é que o local das práticas é onde efetivamente se produz o conhecimento profissional e também onde se dá a formação efetivamente. Toma-se então imperativo conhecer e entender os aspectos psicossociais que constituem a identidade docente para pensar a formação continuada.

Em seu conjunto, as linhas conceituais sobre formação continuada encerram duas críticas centrais. Na primeira, aquilo que Marcelo (2009) aponta como mito da prática, que se refere a uma prática não refletida e dissociada do campo epistemológico. Um alerta dirigido a outro eventual extremo da formação, aquela que não considera a questão epistemológica como elemento de diálogo fundamental para prática, apontando para uma prática autossuficiente que estaria alienada de reflexões balizadas pelo conhecimento construído academicamente por meio de pesquisa.

A segunda crítica se dá sobre o aspecto puramente instrumental da formação continuada centrada em termos como capacitação, treinamento, atualização e reciclagem, que traduzem um olhar de fracasso à formação inicial. Haveria um pressuposto implícito de que a formação parte de lacunas a serem preenchidas. O conhecimento que a formação inicial deixou de ensinar, deve ser ensinado. Ou então o profissional é idealizado como um ser abstrato, com competências também idealizadas. Em ambos os casos, temos o inverso da primeira crítica. Aqui, a epistemologia figura alheia ao conhecimento da prática.

Como pode ser visto no quadro 5, Nóvoa (2002) entende os professores como produtores e não consumidores de conhecimento. Trata-se de uma proposição também válida como parâmetro investigativo para os gestores escolares.

\section{Formação Inicial de Gestores}

Do ponto de vista da legislação federal, conforme Rodrigues et al. (2016), exceto no atual Plano Nacional de Educação, que indica a necessidade de desenvolver programas de formação de diretores e gestores escolares, não há menção objetiva sobre a formação continuada específica dos gestores como direito do profissional e dever do poder púbico. Apenas a LDB de 1996 aborda a questão, ainda assim, de forma genérica: 
Art. 64. A formação de profissionais de educação para administração, planejamento, inspeção, supervisão e orientação educacional para a educação básica, será feita em cursos de graduação em pedagogia ou em nível de pósgraduação, a critério da instituição de ensino, garantida, nesta formação, a base comum nacional (BRASIL, 1996).

Sobre o referido artigo 64 da LBD 9394/96, que suscita uma formação mista do pedagogo e dos gestores escolares, Franco (2017) chama a atenção para críticas de importantes pesquisadores da área educacional, dentre eles Selma Garrido e José Carlos Libâneo, sobre esta organização curricular universitária.

Estes destacavam o equívoco da valorização excessiva do processo de certificação, preterindo-se uma melhor qualificação e enfatizando-se principalmente a lógica do desenvolvimento das capacidades mais laborais do que as intelectuais, políticas e científicas (FRANCO, 2017, p. 104).

Em estudo sobre o percurso dos aspectos de formação dos gestores nos cursos de pedagogia, Franco (2017) agrupa diversos componentes curriculares e observa que o processo formativo se apresenta de forma reducionista e não integrado ao curso como um todo, desconsiderando implicações em competências profissionais apoiadas em autonomia, emancipação e criticidade.

[...]o caso da gestão, é resultante da combinação de vários fatores, dentre os quais: reduzida carga horária; oferecimento predominantemente em períodos finais do curso; escassez de disciplinas que contemplem os diferentes aspectos da gestão e da profissionalidade dos gestores em diferentes ofícios, dentre outros (FRANCO, 2017, p. 116).

Nos atuais cursos de pedagogia, observa-se no currículo uma tendência marcante de aproximação de elementos empresariais assim como a impregnação de uma lógica de economicidade, comprometida com a racionalização do trabalho educativo e o controle por meio de indicadores estatísticos, que negam aspectos políticos e emancipatórios inerentes a escola. (FRANCO, 2017).

\section{Programas de formação em serviço do gestor escolar}

Embora seja senso comum a crença de que a escola não muda, talvez essa afirmação se refira mais acentuadamente às relações de objeto e sujeito entre aluno e 
aprendizagem. Mas, efetivamente, a escola sofre mudanças que refletem mudanças da própria sociedade.

Segundo Leite e Lima (2016), o cenário complexo em que a escola está hoje inserida problematiza o perfil do gestor escolar frente a um ambiente em destaque, conectado, diverso e que exige prova de eficiência por meio de avalições estatísticas, devendo ser garantida a participação dos atores educativos. "Entretanto, é relevante perguntar como está sendo realizada a preparação dos gestores e em que condições de trabalho? Que políticas estão na agenda de prioridades e que condições concretas existem para executá-las?” (LEITE; LIMA, 2016, p. 191).

O ambiente organizacional escolar, neste momento, é instável e exige dos gestores competências complexas. "As responsabilidades e o papel dos gestores mudam com frequência e de modo imprevisível. Lideranças dependem dos interesses e metas definidos por cada nova política socio educacional, cada projeto e cada um dos objetivos almejados e vice-versa." (LEITE; LIMA, 2016, p. 189).

Desse modo, as políticas públicas educacionais passaram a destacar a figura do gestor da escola básica, dos sistemas e redes de ensino, assim como de universidades e instituições de ensino superior, como elemento chave para a melhoria da qualidade da educação em todo o mundo. (LEITE; LIMA, 2016, p. 168).

Já no final da década de 1990, Machado (2000) trazia a mesma preocupação ao informar que o Sistema de Avalição da Educação Básica (SAEB), ao tratar da relação entre gestão e desempenho escolar dos alunos, indicava que os melhores desempenhos conquistados pelos alunos "[...] são observados em escolas que exercem controle direto sobre seus recursos, que têm conselhos ativos, coordenação pedagógica, equipes com expectativas positivas sobre os alunos e que mantêm os pais informados sobre os resultados." (MACHADO, 2000, p. 1002).

Analisando os resultados de aprendizagem dos alunos, várias pesquisas nacionais e internacionais mostram que a escola faz diferença, ou seja, que a eficácia dos seus resultados está associada à sua identidade institucional, na qual se inclui o padrão de gestão, ao saber: sua forma de organização administrativa e pedagógica, as relações entre os agentes, o desenvolvimento de visão compartilhada, as expectativas de desempenho bem-sucedido, o ambiente de aprendizagem, a boa prática de sala de aula, a responsabilização pelos resultados de aprendizagem de seus alunos e a presença de liderança forte e legítima. (MACHADO, 2000, p. 1000). 
Observa-se que, dentre outras inciativas, figuram com maior destaque nas últimas décadas dois programas que se sucedem e destinam-se à formação de gestores escolares: o PROGESTÃO e o Programa Escola de Gestores de Educação Básica, este último ainda em funcionamento.

Após investigação bibliográfica Franco (2017), Gomes, Santos e Melo (2009), Leite e Lima (2015), Machado (2000), Ogawa e Filipak (2013), (PENIN, 2001) e Rodrigues et al. (2016), também em análise documental dos objetivos, conteúdo e metodologia dos dois referidos programas, concluímos:

Destacam-se dois problemas: de conteúdo e de método. O conteúdo, por conta da proletarização da gestão e no sentido da racionalização da prática, que promove, por consequência, o estranhamento do gestor escolar à função social da escola. Não ocorre o fortalecimento de fundamentos para a uma ação política, crítica e intencional do gestor frente a demanda emancipatória da escola pública, reconhecidamente legítima, democrática e indissociável do conceito de gestão escolar.

No que tange o método, os programas de formação e serviço, apesar de ensaios metodológicos diversificados, assumem um discurso normativo e prescritivo. Esse discurso se manifesta por termos tradicionais como capacitação e treinamento, inspirados na suposição da ausência de capacidade dos gestores para realizar atribuições de gestão.

Os programas de formação em serviço ganham destaque a partir de indicadores que apontam uma relação entre o bom desempenho das escolas e as características de gestão escolar. Esse fator, associado a demanda de qualidade, imprime aos programas uma identidade eminentemente instrumental, disseminada por uma identidade gerencial que se observa nos termos competências, liderança, resultados, eficácia e controle. Assume-se, dessa forma, um discurso neoliberal.

\section{O conceito específico de formação em serviço de gestores escolares}

Zeichner (2008) iniciou sua pesquisa a partir da percepção de que os alunos de licenciatura não questionavam o que ensinavam, preocupavam-se apenas em ensinar. Não questionavam de onde vinha o currículo, ocupavam-se dele como um instrumento técnico que orientava a prática sem uma reflexão mais elaborada sobre uma dimensão ética para prática.

Bem próxima a essa persistência da racionalidade técnica sob o slogan do ensino reflexivo, encontra-se a limitação do processo reflexivo em considerar 
as estratégias e habilidades de ensino (os meios para se ensinar) e a exclusão, da alçada dos professores, da reflexão sobre os fins da educação, bem como os aspectos moral e ético do ensino. Aos professores, permite-se apenas que ajustem os meios para se atingir objetivos definidos por outras pessoas. $\mathrm{O}$ ensino torna-se meramente uma atividade técnica (ZEICHNER, 2008, p. 542).

A reflexão tem um papel fundamentalmente político em Zeichner (2008), em função de não se restringir a um fazer técnico, ligado a qualquer currículo formalmente adotado e testado por avaliações externas, mas sim em permanente crítica sobre o porquê fazer. Que papel aquele que faz ocupa naquilo que é feito? Qual seu grau de consciência e intencionalidade sobre o resultado do seu trabalho?

A pergunta formulada no início do capítulo em Tardif e Raymond (2000), sobre a problemática negociação entre o uso de si por si mesmo e o uso de si pelos outros, é um problema tanto para gestores escolares quanto para gestores de sistemas. Procurar respondê-la, demarcando um conceito de formação em serviço de gestores escolares. Dessa forma, cumpre à formação do gestor escolar, enquanto conceito, estruturar-se por quatro princípios que associam conteúdo e método: primeiramente, um princípio ético, que exige de todos os atores educativos a assunção do compromisso emancipatório da própria educação (RIOS, 2011); um princípio indenitário, que concebe o ator educativo, seja professor ou gestor - e certamente o aluno - como sujeito e objeto do seu trabalho, transformando-o e transformando-se (ROLDÃO, 2007), (NÓVOA, 1998), (TARDIF, 2002) e (MARCELO, 2009); um princípio de aprendizagem coletiva, promovida pelo ambiente de trabalho, que se estabelece pelas relações coletivas e que determinam a cultura escolar (ESTRELA, 2001) e (VAILLANT; MARCELO, 2012); e por fim um princípio de reflexão sobre o conhecimento na prática e sobre a prática e para a prática (SCHÖN, 1997), sendo este último aquele que dá sentido e coesão aos outros três.

\section{Considerações finais}

A Gestão Escolar é uma prática singular de administração porque a gestão escolar, inscrita no ato educativo como a pedagogia, se alimenta de diversas fontes conceituais.

O conceito de gestão escolar carrega duas dimensões indissociáveis: técnica e política. A primeira é universal, pois se inscreve no campo da administração enquanto ciência que estuda e instrumentaliza a mediação entre os objetivos e os resultados de uma organização. Enquanto a outra é específica, porque destina-se a especificidade do espaço escolar, onde não se admite, 
por princípio legal e ético, outra mediação além da mediação democrática, que promove, já no processo, a vivência e aprendizagem coletiva sobre a partilha do poder.

O conceito de gestão escolar, portanto, implica a capacidade do gestor em pesquisar e construir junto à comunidade escolar, de forma democrática e autônoma, o entendimento sobre a função social da escola, a razão do fazer escolar e em que qualidade ela se traduz. Pretendese ter uma tomada de posição política e intencional que se manifeste em um objetivos e métodos, implicando no domínio das capacidades técnicas/instrumentais para gerenciamento deste processo.

Considerando as especificidades da gestão escolar, entende-se a formação profissional em serviço também com características próprias. Dessa forma, constituem-se em:

Situações de aprendizagem oferecidas por sistemas, redes e instituições de ensino para o gestor escolar, em razão de sua prática de gestão, considerando a promoção de seu entendimento crítico e coletivo sobre a função social da escola, e sobre suas atribuições frente a esta tarefa, no campo político e técnico, por meio de metodologia reflexiva que proporcione condições e fomento à prática refletida do gestor escolar em permanente investigação crítica à sua própria produção epistêmica e as demais produções epistêmicas que decorrem da prática de gestão.

\section{REFERÊNCIAS}

ALARCÃO, I. Formação continuada como instrumento de profissionalismo docente. In: VEIGA, I. P. A. (org). Caminhos da profissionalização do magistério. Campinas: Papirus, 1998.

BRASIL. Constituição (1988). Constituição da República Federativa do Brasil. Brasília, DF: Senado Federal: Centro Gráfico, 1988.

BRASIL. Senado Federal. Lei de Diretrizes e Bases da Educação Nacional: no 9394/96. Brasília: 1996.

CASTRO, M. M. C.; AMORIM, R. M. A. A formação inicial e a continuada: diferenças conceituais que legitimam um espaço de formação permanente de vida. Cadernos CEDES. Campinas: v. 35, n. 95, p. 37- 5, abr. 2015. Disponível em: http://dx.doi.org/10.1590/CC0101-32622015146800. Acesso em: 13 de jul. 2017.

CHAMON, E. M. Q. O. Formação e (re)construção indenitária: estudo das memórias de professores do ensino básico inscritos em um programa de formação continuada. 2003. Tese (Doutorado em Educação) - Universidade Estadual de Campinas, Faculdade de Educação, Campinas, 2003. 
ESTRELA, M. T. A formação contínua entre teoria e prática. In: FERREIRA, N. S. C. (Org). Formação continuada e gestão de educação. São Paulo: Cortez, 2001. p. 43-64.

FILHO, P. V. Afinal, o que é planejamento estratégico? Revista de Administração de Empresas, São Paulo, v. 18, n. 2, abr./jun., 1978. Disponível em: http://dx.doi.org/10.1590/S0034-75901978000200002. Acesso em: 25 ago. 2017.

FRANCO, A. P. Formação de gestores escolares: dos encontros e desencontros nos cursos de pedagogia. In: SILVESTRE, M.; A. PINTO, U. A. (orgs). Curso de pedagogia: avanços e limites após as Diretrizes Curriculares Nacionais. São Paulo: Cortez, 2017.

FREIRE. P. Pedagogia da autonomia: saberes necessários à prática educativa. São Paulo: Paz e Terra, 1997.

GATTI. B. A. Formação continuada de professores: a questão psicossocial. Cadernos de Pesquisa. São Paulo: Fundação Carlos Chagas, n. 119, p. 191-204, jul., 2003. Disponível em: http://www.scielo.br/pdf/cp/n119/n119a10.pdf. Acesso em: 25 ago. 2017.

MARCELO, C. A identidade docente: constantes e desafios. Formação Docente. Revista Brasileira de Pesquisa sobre Formação de Professores, Belo Horizonte, Associação Nacional de Pós-graduação e Pesquisa em Educação (ANPEd), v. 01, n. 01, p. 109-131, ago./dez. 2009. Disponível em: http://revformacaodocente.com.br/index.php/rbpfp. Acesso em: 25 ago. 2017.

MARTINS, R. C. R. Progestão: como gerenciar o espaço físico e o patrimônio da escola? Brasília: Consed, 2001. Disponível em: http://www.sed.sc.gov.br/documentos/plano-degestao-escolar-409/processo-2016/progestao-modulos-atividades/4362-modulo-vii-comogerenciar-o-espaco-fisico-e-o-patrimonio-da-escola/file. Acesso em: 25 ago. 2017.

MILITÃO, A. N.; LEITE, Y. U. F. A historicidade do conceito de formação continuada: uma análise da visão de Paulo Freire sobre a formação permanente. Anais... VII Congresso Brasileiro de História da Educação: Circuitos e Fronteiras da História da Educação no Brasil. Cuiabá: Universidade Federal do Mato Grosso, v. 1. p. 1-15, 2013.

MORETO. J. A. A educação continuada do diretor da escola: avaliação da política implementada pela Secretaria Municipal de Educação de Campinas, no período de 1994 a 2000. Dissertação (Mestrado em Educação) - Universidade Estadual de Campinas, Faculdade de Educação, Campinas, 2002.

NÓVOA, A. A formação tem de passar por aqui: as histórias de vida no projecto Prosalus. In: NÓVOA, A.; FINGER, M. (Orgs.). O método (auto)biográfico e a formação. Lisboa: Ministério da Saúde, 1988.

NÓVOA, A. Professor se forma na escola. In: Nova Escola. São Paulo: Abril Cultural, Edição n. 142, maio, 2002. 
PAULA, S. G. Formação continuada de professores: perspectivas atuais. Paidéia - Revista do Curso de Pedagogia da Faculdade de Ciências Humanas e Sociais, Belo Horizonte:

Universidade FUMEC, ano 6, n. 6, p. 65-86, jan./ jun., 2009.

RIOS, T. A. Ética e competência. São Paulo: Cortez, Ed. 20, 2011.

RODRIGUES, E. S. S.; REIS, M. G. F. A.; ARANDA, M. A. M. A formação continuada para gestores da educação básica e a demanda do cotidiano escolar: uma análise no âmbito das políticas públicas. Revista on line de Política e Gestão Educacional, Araraquara, v. 20, n. 3, p. 444-462, 2016. Disponível em: http://dx.doi.org/10.22633/rpge.v20.n3.9722. Acesso em: 25 ago. 2017.

ROLDÃO, M. C. Função docente: natureza e construção profissional. Revista Brasileira de Educação, Rio de Janeiro, Anped, v. 12, n. 34, jan./ abr., 2007.

SALLES, F. C. A formação continuada em serviço. Revista Iberoamericana de Educación, 2015. Disponível em: https://rieoei.org/historico/deloslectores/806Casadei.PDF. Acesso em: 13 jul. 2017.

SANTOS, V. L. F. dos. Formação contínua em serviço: construção de um conceito a partir do um estudo de um programa desenvolvido no município de Andradina -Presidente Prudente. Dissertação (Mestrado) - Universidade Estadual Paulista, Faculdade de Ciências e Tecnologia, 2005.

SHULMAN, L. S. Conhecimento e ensino: fundamentos para a nova reforma. Cadernos Cenpec, São Paulo, v. 4, n. 2, p. 196-229, dez. 2014.

SCHÖN. D. Formar professores como profissionais reflexivos. In: NÓVOA, A. (org.). Os Professores e a sua Formação. Lisboa: Publicações Dom Quixote, Ed 3, 1997.

TARDIF, M. Apresentação. Educação e Sociedade. Campinas: CEDES, v. 22, n. 74, p. 1126, abr., 2001. Disponível em: http://www.cedes.unicamp.br. Acesso em: 02 ago. 2017.

TARDIF, M. Saberes docentes e formação profissional.8 ed. Petrópolis: Vozes, 2002.

TARDIF, M. A profissionalização do ensino passados trinta anos: dois passos para a frente, três para trás. Educação e Sociedade, Campinas, v. 34, n. 123, p. 551-571, abr./jun. 2013. Disponível em: http://www.cedes.unicamp.br. Acesso em: 02 ago. 2017.

VAILLANT, D. MARCELO, C. Ensinando a ensinar: as quatro etapas da de uma aprendizagem. Curitiba: Editora UTFPR, Ed. 1, 2012.

ZEICHNER, K. M. Uma análise crítica sobre a "reflexão" como conceito estruturante na formação docente. Educação e Sociedade, Campinas, v. 29, n. 103, p. 535-554, maio/ago. 2008. Disponível em: http://www.cedes.unicamp.br. Acesso em: 02 ago. 2017. 


\section{Como referenciar este artigo}

NASCIMENTO, Marcelo do; OLIVEIRA, Alessandro Luiz de; ABDALA, Rachel Duarte. A Formação em serviço do gestor escolar como ação formativa intencional e política. Revista on line de Política e Gestão Educacional, Araraquara, v. 23, n. 2, p. 266-285, maio/ago., 2019. E-ISSN:1519-9029. DOI: 10.22633/rpge.v23i2.11887

Submetido em: 08/11/2018

Revisões requeridas: $23 / 12 / 2018$

Aprovado em: 19/01/2019

Publicado em: 06/03/2019 